\title{
AC 2011-1099: USING THE ECOCAR CHALLENGE AS A NON-TRADITIONAL DOMAIN FOR SOFTWARE AND COMPUTER ENGINEERING CAPSTONE COURSE
}

\section{Richard Stansbury, Embry-Riddle Aeronautical Univ., Daytona Beach}

Richard S. Stansbury is an assistant professor of computer science and computer engineering at EmbryRiddle Aeronautical University in Daytona Beach, FL. He instructs the capstone senior design course for computer and software engineering. His current research interests include unmanned aircraft, certification issues for unmanned aircraft, mobile robotics, and applied artificial intelligence.

\section{Massood Towhidnejad, Embry-Riddle Aeronautical Univ., Daytona Beach}

Massood Towhidnejad is a tenure full professor of software engineering in the department of Electrical, Computer, Software and System Engineering at Embry-Riddle Aeronautical University. His teaching interests include artificial intelligence, autonomous systems, and software engineering with emphasis on software quality assurance and testing. He has been involved in research activities in the areas of software engineering, software quality assurance and testing, autonomous systems, and human factors. 


\title{
Using the EcoCAR Challenge as a Non-Traditional Domain for Software and Computer Engineering Capstone Course
}

\begin{abstract}
:
This paper presents the opportunities provided by EcoCAR: The NeXt Challenge in supporting a capstone design course in computer and software engineering. Students participating in the course were responsible for implementing a sub-system of a plug-in hybrid electric vehicle. Being a sponsored competition organized by the Department of Energy, the project provided many unique learning opportunities for students in the course and those that they interacted with from other disciplines. This paper will discuss both the benefits of utilizing such a competition for a senior capstone design course as well as some of the challenges faced. The paper concludes with some recommendations for those considering such a project as a capstone design course in the future.
\end{abstract}

\section{Introduction:}

This paper presents a unique capstone opportunity in which seniors in computer engineering and software engineering took an active role on a multidisciplinary capstone projects at EmbryRiddle Aeronautical University (ERAU). The EcoCAR Challenge ${ }^{6}$ is an international competition in which 17 universities compete to produce the next generation of hybrid vehicles over a three year period from 2008 - 2011. This competition is the successor of a number of previous challenges hosted by the United States Department of Energy including Challenge X. All competitors are donated a vehicle (shown in Figure 1) as well as electronics hardware, software, tools, and mechanical parts.

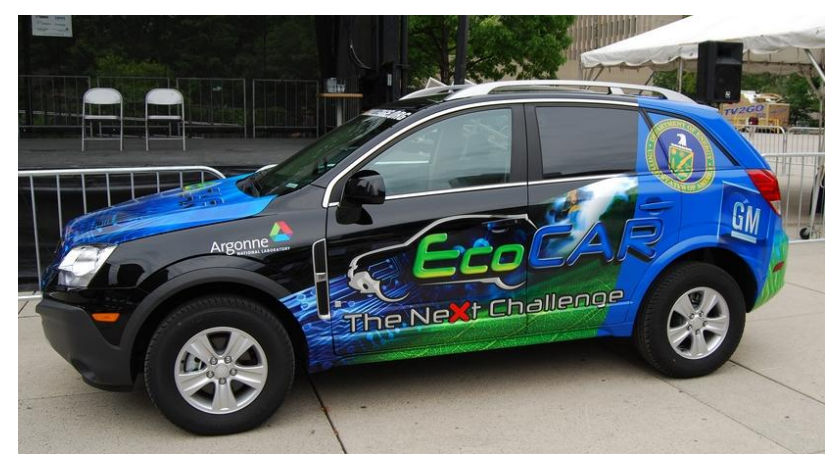

Figure 1: A General Motors donated EcoCAR.

EcoCAR is a three-year competition. The first year involves students using software and hardware-in-the-loop simulators (SIL and HIL, respectively) to design the vehicle based upon the competition performance requirements and both the team's interests and capabilities. For the second year of competition, each team generates a mule (or prototype vehicle) that demonstrates their hybrid powertrain design. Finally, year three tasks the teams with completing their vehicle such that it reaches the $95 \%$ buyoff requirements from GM (i.e. they are $95 \%$ complete toward production). 
Each year, milestones are set for the team by way of progress reports, mentor visits, organizers visits, workshops, and an end-of-year finals. The progress reports are used to assess team's progress, encourage technical writing, and ensure that teams are moving toward their goals. Mentors from GM will communicate with the team throughout the academic year, but will visit at least once a semester. The ANL organizers will schedule visits at least once or twice a year for competition judges to access team progress, perform safety and emissions assessments, etc. Two workshops are held each year for team training in mechanical, controls, and emissions topics. The end-of-year finals bring all of the teams together to compete in both static (presentations and tradeshow booth) and dynamic (road or simulator tests) judged events.

Traditionally, teams competing in competitions such as EcoCAR are comprised of mechanical engineering students and only a small handful of students from other domains. During the 2008-2009 academic year, as part of their computer and software engineering capstone project students majoring in computer engineering, software engineering, and human factors formed a new sub-team focused upon developing a new pre-emptive control system for hybrid vehicles.

The course's final product was the initial prototype of the Intelligent Drive Efficiency Assistant (IDEA). This high-level control system is designed to observe the hybrid control system, the vehicle's state, and the anticipated future state of the vehicle (based on GPS, terrain maps, etc.) and make recommendations regarding which hybrid configuration the vehicle should operate. Unlike traditional hybrid vehicle control systems, this system preemptively selects the "best" hybrid mode so that it is ready ahead of demand versus traditional control systems that only react when the current demand on the drive train changes.

By integrating a software team into a traditionally mechanically engineering focused project, the students received the unique opportunity to work on a truly multi-disciplinary team. Unlike traditional projects in which these students worked primarily with other computer and software engineers, this project forced them to interact with students and faculty from other domains and learn to communicate effectively across domains. Students were encouraged to use tools not typically used in software engineering courses such as the National Instruments' software tool suite. Software validation and verification using software and hardware in-the-loop simulators was introduced. Hardware interfaces for interacting with the vehicle's systems were developed. Some students were also given the opportunity to receive professional training from the sponsors in some of the tools used.

In the following sections, we first cover EcoCAR the literature survey for similar projects have used competition based projects for capstone design courses. Next, our capstone project and its integration with EcoCAR is discussed. The project and course are accessed versus ABET's program outcomes for engineering programs ${ }^{1}$. The advantages and disadvantages of choosing EcoCAR as a platform for the capstone design project is discussed. Finally, some recommendations are shared.

\section{$\underline{\text { Background }}$}

This section describes the capstone design course at ERAU for computer and software engineers. Next, an overview of the EcoCAR competition is provided. 
Capstone Design Course:

For the past ten years, ERAU's computing programs have offered a two semester capstone design course focused upon development of a hardware/software system. It is open to students majoring in computer engineering, software engineering, and computer science. For the 20082009 academic year, there were 15 students of which 5 majored in computer engineering and 10 in software engineering. All students have completed SE 300: Introduction of Software Engineering and are familiar with engineering process.

The project-based philosophy for the course has resulted in students working in several subteams toward the completion of a single common project. Team hierarchy and process vary year-to-year and are discussed in more detail below. Table 1 shows the typical sequence of activities. Each year, regardless of the project, the course follows this common structure to ensure that program and learning outcomes are achieved and specific artifacts of those outcomes are produced by the students.

Table 1: Schedule of activities for capstone design course.

\begin{tabular}{|ll|}
\hline \multicolumn{1}{|c|}{ Activity } & \multicolumn{1}{c|}{ Time Frame } \\
\hline Problem statement and initial research & Late August - Early-September \\
\hline Requirements Elicitation & September \\
\hline Requirements Inspection & Late September - Early October \\
\hline Initial Design and planning & October \\
\hline Prototyping and initial implementation & November - Mid-December \\
\hline Design review & Mid-December \\
\hline Product Implementation & January - Mid-April \\
\hline Wrap-up & April \\
\hline Final presentation & Late April \\
\hline
\end{tabular}

Following this timeline, students generate a large number of course deliverables. Deliverables include: final working product (hardware, source code, and binaries), research paper (completed individually), time logs (completed individually), system requirements specification, system design specification, project plan, design review presentation, socio-economic impact statement, ethical impact study, test document, traceability matrix, test logs, user manual, and final presentation.

\section{Literature Survey: Competition-based Capstone Projects}

Competition-based capstones are not uncommon as was found from a literature survey. In a conference paper by Paulik and Krishnan ${ }^{4}$, they discuss the use of competitions for capstone design courses at the University of Detroit, Mercy's department of Electrical and Computer Engineering. The authors utilized AUVSI's Intelligent Ground Vehicle Competition (IGVC) as a vehicle for their capstone design course. However, from the results, it was shown that many were not nearly as multidisciplinary or involving as large of teams as the EcoCAR Challenge. EcoCAR has been used in number of universities, as discussed in Hassel et al. ${ }^{2}$, Michigan 
Technology University's (MTU's) use of EcoCAR for control systems instruction is discussed. The authors indicate that EcoCAR provides an undergraduate control systems experience that they would not typically receive as part of their undergraduate education as such courses typically do not focus upon the controller hardware nor are topics reinforced with hands-on experience.

In 2005, faculty from Smith College performed a national survey on engineering capstone education $^{3,7}$. It compares the results with that of a previous study conducted in 1994; however, there was only a partial overlap in respondents between the two surveys. This survey yields some noteworthy results for comparison, which are highlighted here.

The survey results ${ }^{3,7}$ show that across the majority of engineering disciplines, the number of respondents indicating that their programs included capstone design courses grew dramatically between 1994 and 2005. Computer engineering, computer science, and electrical engineering programs provided the second largest number of respondents at $35 \%$. Software engineering was not included in the survey and was not distinguished as falling under the computing category or under the other category. Unfortunately, the remainders of the results were not divided out by discipline. Of the respondents, at least $81 \%$ indicated that their capstone project involved departmental teams and 35\% indicated some level of interdepartmental teaming, which had increased from $20 \%$ in 1994.

The respondents also indicated that there is a strong correlation between the ABET prescribed program outcomes such as communication, writing, ethics, teamwork, safety, etc ${ }^{3}$. About $60 \%$ of respondents indicated that the teams are comprised of 4 to 6 students. The surveys also indicated that $71 \%$ of respondents worked with industry as a source for projects. Funding is often shared between external sponsors and the institution. Other issues such as external funding and intellectual property are discussed throughout the literature, but are beyond the scope of this paper.

\section{Project Overview: The IDEA System for the Eco-Eagles EcoCAR Team}

The university's team was comprised of students from a variety of majors. In the initial proposal, a new software system for intelligent hybrid control was proposed. Low-level control system development on the vehicle's hybrid supervisory control unit was implemented by mechanical engineering students. The computer and software engineering students were assigned to implement the Intelligent Drive Efficiency Assistant (IDEA) system as their capstone design project as depicted in Figure 2.

The IDEA system assists the hybrid control unit by using artificial intelligence to predict upcoming driving conditions and make recommendations to transition to a different hybrid mode if deemed beneficial. This preemptive strategy is believed to provide two key benefits. First, through learning algorithms, new control strategies may be developed based on the driving conditions and past experience. Second, by preemptively making recommendations ahead of a driving event such as an uphill climb, or a frequent stop in rush-hour traffic, it is believed that there will be less energy wasted by not waiting until the need arises to start making the transition. 
In addition to the driving environment, the vehicle's state of charge must be considered to ensure that the proper level of charge is maintained to meet demand.

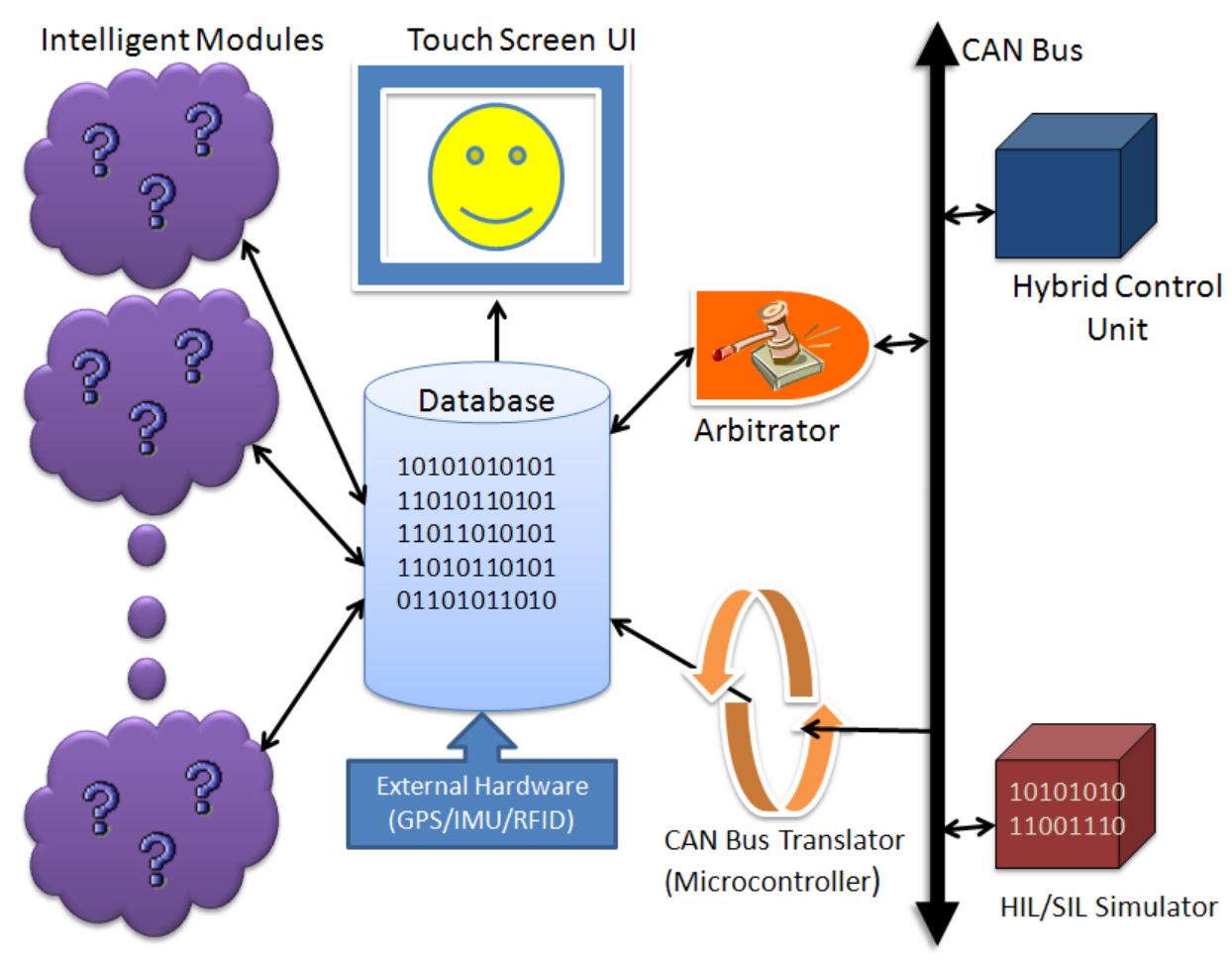

Figure 2: Conceptual architecture of the IDEA System.

To improve its robustness and decrease development time, the IDEA system has been designed using highly modular software. The system is comprised of a series of Intelligent Modules (IMs), which may be added or removed during development without any significant impact to the IDEA system's framework and decision making logic. The IMs are designed to provide specific pieces of artificial intelligence related to one or more driving condition such as terrain, traffic, driver profile, etc. A second software component known as the Arbitrator monitors the recommendations by all IMs and using a voting algorithm produces a single decision, which is shared with the Hybrid Control System (HCS).

During the first year, the competition stresses software/hardware-in-the-loop (HIL) testing, which allows testing of controls software and is depicted in Figure 3. This allows for rigorous testing, including worst case scenarios, with fault insertion to ensure the controls are relatively safe before execution in the vehicle. In preparation for this competition, the IDEA system was tested against the SIL simulator to determine if its benefits exceed its costs. 


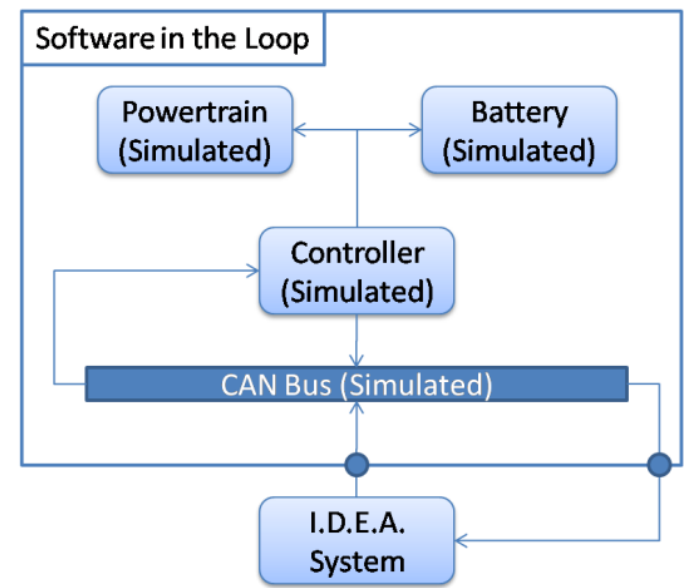

Figure 3: Software-in-the-loop simulation strategy for IDEA System.

\section{Benefits of EcoCAR in supporting capstone design for computer and software engineering}

\section{Benefits to Computer and Software Engineering Students}

This project provided many benefits to our students. The achievement of the program outcomes for graduating students is discussed below. Briefly, some of the benefits to students attained from the first year of EcoCAR as part of the capstone design project include:

- Exposure to disciplines outside of the department.

- Exposure to modern industrial tools and processes.

- Financial support through resources and funding from competition sponsors for project.

- Networking with industry sponsors at workshops, campus visits, and end-of-year finals.

- Training on modern software tools such as National Instruments Labview, Mathworks Simulink, etc.

\section{Meeting Program Outcomes for Assessment and Accreditation}

In this section, we discuss how EcoCAR addresses some of the ERAU's outcomes by pushing beyond a typical project concentrating around the computing domain.

Outcome (a) [An ability to apply knowledge of mathematics, science, and engineering]. The goal of the IDEA system was to develop an intelligent decision tool to guide the supervisory control unit of the EcoCAR. IDEA incorporated a large geographic information system (GIS) database containing data on terrain elevation for the entire United States with a 0.5 mile resolution. Mathematics was used to predict terrain ahead given the vehicle's current trajectory (Figure 4 depicts how weights were assigned given the vehicle's current location to potential upcoming locations). Principles of science including Newtonian physics were incorporated into the intelligent modules to make decisions based on terrain and driver acceleration history. 


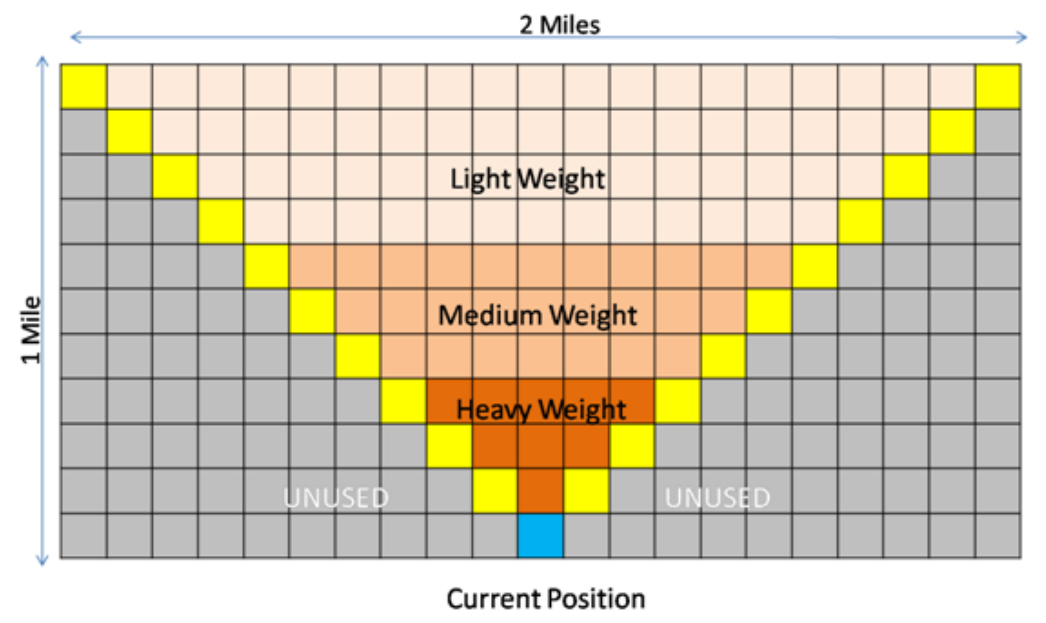

Figure 4: Graphical depiction of weight assignments for predicted driving conditions.

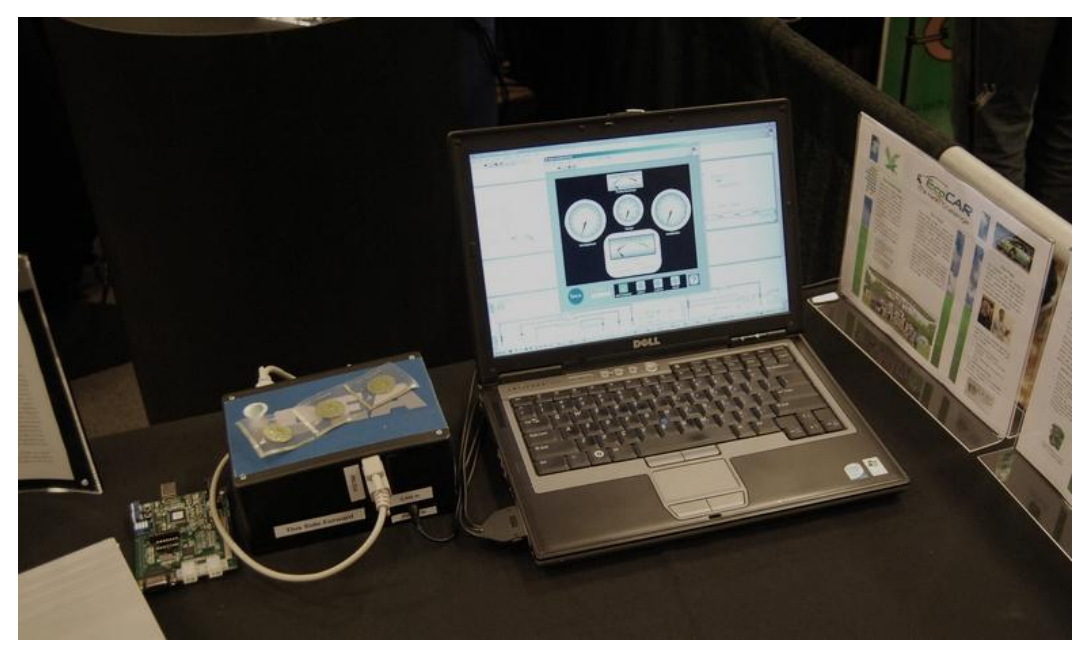

Figure 5: Prototype of the IDEA System including software, hardware box, and RFID tags.

Outcomes (c, e, and h) [An ability to design a system, component, or process to meet desired needs within realistic constraints such as economic, environmental, social, political, ethical, health and safety, manufacturability, and sustainability], [An ability to identify, formulate, and solve engineering problems], and [The broad education necessary to understand the impact of engineering solutions in a global, economic, environmental, and societal context]. One of the major benefits from EcoCAR is that it provides realistic industrial constraints on the project. The team must follow a 3-year industrial life cycle in which the vehicle is designed the first year, prototyped in the second, and readied to a 95\% buy-off level during the third. The EcoCAR project provides an opportunity to expose students with a set of unique constraints that may not typically be the case for other projects. There are much stronger constraints and emphasis around economic, environmental, manufacturability, sustainability, and safety constraints while operating under a limited budget. For example, the cost to the consumer, governmental safety constraints, environmental impact, economical and social impact of the solution played a major role in our design decisions. Customer acceptance was another major 
design constraint that was addressed. Figure 5 shows the year one prototype of the IDEA system.

Outcome (d) [An ability to function on multidisciplinary teams]. While the IDEA team itself was comprised of students majoring in computer engineering and software engineering, whom have many overlapping courses within the department's curricula, they interacted with students from mechanical engineering, aerospace engineering, human factors, communications, and business. This involved periodic joint meetings, frequent lab visits, hardware/software integration, joint-deliverables, and the generation of written documentation for the EcoCAR milestones.

As a multidisciplinary project, the students from other programs had the opportunity to interact with our students on the same team project. Information sharing goes both ways. After some initial communication issues, both teams were able to understand and respect the various engineering processes carried out based upon field of engineering, instructor preference, and industrial standards. Contrary to the project schedule as dictated by ANL, the instructors required the software engineering and computer engineering students to follow an agile process. This provides students from other disciplines the opportunity to witness this process first hand. Students from both departments also learned lessons on how different fields thinking about and describe very similar engineering concepts.

Outcome (f) [An understanding of professional and ethical responsibility]. Professional and ethical responsibility are soft skills that are challenging to assess, but important throughout the engineering lifecycle. Of course there are a number of professional and ethical issues that are addressed as part of any team's work, and the professional society associated with the domain have professional codes of ethics (i.e. IEEE Code of Ethic); however, EcoCAR, provided us a set of unique opportunities to discuss additional ethical responsibilities that may not be critical in a typical computing project. For instance, the ethical issues related to safety and environment that come from the consequences of their hardware and software deciding which hybrid mode the vehicle should operate and when it should transition between modes.

Outcome (g) [An ability to communicate effectively]. As described earlier in this paper, EcoCAR's milestones and competition finals require students to communicate and are judged based on their written and verbal skills alongside their technical contributions. Each progress report from the EcoCAR team included new content from the IDEA team. During the 2009 finals in Toronto, the IDEA system was presented by students who submitted a paper and presented toward the National Instruments sponsors award receiving first place. They also contributed to the tradeshow booth shown in Figure 6.

In addition to the competition, the capstone design course required students to produce a system requirements specification, system design specification, test plan, socio-economic report, and ethics report. Two oral presentations were given; a design review and a final project demonstration. One of the advantages of the EcoCAR project was the need to communicate with person coming from both technical and non-technical backgrounds participating as part of the presentations, reviews, and event judging. An additional challenge was associated with the need to communicate with technical people who are not necessary in the computing domain. Finally, 
representing the outcomes of our research in nontraditional (non-computing) conferences (i.e. ASME Energy Sustainability 2009 conference $^{5}$ ) was an added advantage.

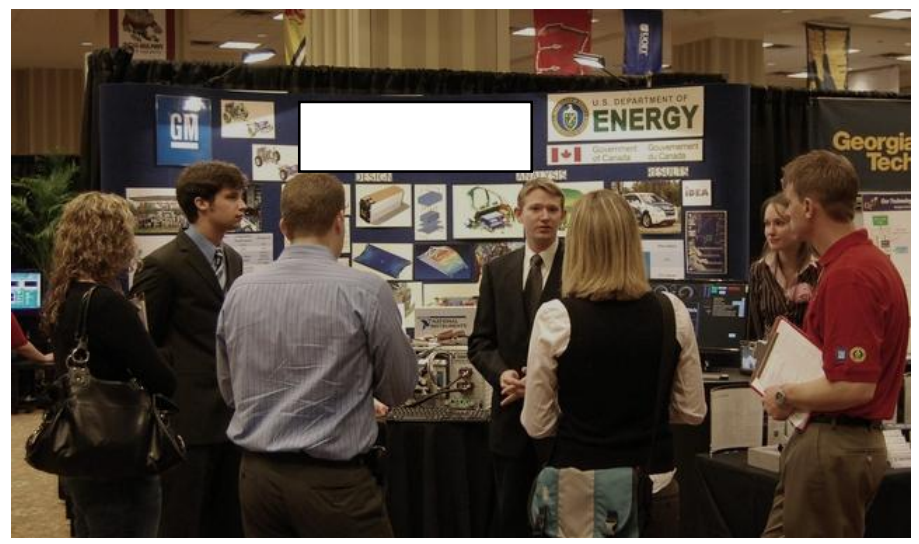

Figure 6: Team tradeshow booth for 2009 finals.

Outcome $(i, j, \& k)[A$ recognition of the need for, and an ability to engage in life-long learning], [A knowledge of contemporary issues], and [An ability to use the techniques, skills, and modern engineering tools necessary for engineering practice]. Life-long learning is a soft skill that involves an individual striving to remain current within their domain of expertise, and forced them to have an upkeep with the contemporary issues, and different tools, techniques and engineering practices by continually educating themselves. This project teaches students much in the way of life-long learning by forcing them to address new engineering topics that they would not typically encounter. For instance, students gained invaluable exposure to: simulation tools (SIL), visual design tools (Labview), Design Failure Mode Effect Analysis (DFMEA), Controller Area Network (CAN) architecture, CAN bus analysis tools, hybrid vehicle system, automotive systems, emissions calculations based on fuel consumption, etc.

Outcome (l) [An understanding of real-time, safety-critical, embedded computer system]s. For safe and reliable operation of a hybrid system, the timing of communications, mechanical transitions, and other control decisions are critical. Failure to meet timing requirements can have an impact on vehicle operability, reliability, and most importantly safety. In designing the IDEA system, it was designed such that it could meet the vehicle's timing constraints. Students also developed embedded hardware to be installed in the vehicle to support the IDEA system including microcontrollers, GPS, RFID readers, etc.

\section{Challenges of EcoCAR in supporting capstone design for computer and software engineering}

Despite the benefits of utilizing a design competition such as EcoCAR, it did yield some unique issues that can be found both in industry sponsored projects as well as completion-based projects. These will be briefly described in this section.

First, with any industry sponsored project in which resources must be provided from the sponsor, there runs the risk that products will not come available as promised. For example, simulator models, some sponsor hardware, and some of the competition rules and expectations were not provided as initially planned. While this is common in industry and often captured in capstone 
design experiences to teach students how to handle a dynamic plan, the year one of EcoCAR included numerous set backs from both organizers and sponsors. Some delays were a result of personnel issues. Others, technical issues that were previously unforeseen with regard to tool availability and viability arose. Additionally, sponsors hold their own corporations' needs first and foremost, which resulted in insufficient resources to address these various problems in a timely manner. Fortunately, agile process provided some flexibility. Nevertheless, frequent delays resulted in significant frustration for the students and instructors. Of course, this provided a realistic opportunity to highlight the importance of risk management.

Another issue is that it is very challenging to adhere to the typical course schedule for capstone milestones versus the competition timeline. Often the competition milestones would require activities to be performed much earlier in the competition than the typical workflow would allow. Requirements to select an architecture early in the semester required some decision from our students as well as students from other programs prior to sitting down and producing a formal requirements document.

Lastly, students were unprepared for working in a team that is so large involving so many disciplines. While each year's senior design attempts to be multidisciplinary, the EcoCAR team, with over 50 students, from six different programs, provided substantial challenges. Across discipline lines, the processes and deliverables for capstone design project varied significantly. In addition to these deliverables, the language of one discipline can vary dramatically. As a result, students become frustrated when simple communication task break down in confusion.

Issues such as a breakdown in communication, varying timetables for deliverables, and delays are not uncommon. However, in a course with student team members that are still professionally immature, the impact of these issues were easily compounded and at times the team would revert to ad hoc development rather than adhering to proper engineering processes and techniques. For future academic years, the instructors felt more comfortable sustaining the IDEA team by creating an extracurricular organization comprised of first year students that had entered our master's degree program.

\section{Conclusion}

Using the EcoCAR project for a capstone design course in computer and software engineering did prove to be viable. The project supported all of the activities required of a capstone design project in order to meet the program outcomes. It also provided learning opportunities that past capstone design courses had not presented such as exposure to new tools, inter-departmental collaboration, working on large multi-year projects, and continuous collaboration with an external customer (organizers and sponsors).

Given hindsight, many of the challenges discussed above could be avoided by others seeking to utilize a competition similar to EcoCAR. Here are some recommendations for faculty wishing to utilize a sponsor driven competition as a vehicle for a capstone design course (or courses). First, anticipate and prepare students for delays in receiving resources from the organizers and sponsors. A clearly defined critical path and some built-in slack time will help remedy the issues resulting from minor to moderate delays. Second, special care must be taken when building a 
large multidisciplinary team. We learned that there was inadequate team building across the many sub-teams and disciplines. Third, encourage your students to utilize your faculty mentor(s) if they are available as often as possible as this provides opportunities to develop their professionalism.

\section{$\underline{\text { References: }}$}

${ }^{1}$ ABET. A Guide to the Criteria Harmonization for Engineering Accreditation, online at: http://www.abet.org/Linked\%20DocumentsUPDATE/Criteria\%20and\%20PP/EAC\%20Readers\%20Guide.pdf, 2011.

${ }^{2}$ Hassell, T. J., Oliveira, A. M. and Weaver, W.W. Control system development for undergraduate exposure. In 2010 IEEE Frontiers in Education Conference (FIE), F1C-1-F1C-7. IEEE, October, 2010.

${ }^{3}$ Howe, S., and Wilbarger, J. 2005 National Survey of Engineering Capstone Design Courses. In 2006 ASEE Annual Conference and Exposition, 1-21, 2006.

${ }^{4}$ Paulik, M.J., and M. Krishnan. A competition-motivated capstone design course: the result of a fifteen-year evolution. IEEE Transactions on Education 44, no. 1: 67-75, 2001

${ }^{5}$ King, A., Del Buono, M., Marolf, J., Dop, M., and Stansbury, R. “An Intelligent System for Improving the Efficiency of a PHEV For EcoCAR Challenge.” ASME Energy Sustainability Conference 2009, San Francisco, CA, July 2009.

${ }^{6}$ US Department of Energy. "EcoCAR Challenge”, Online at: http://www.EcoCARchallenge.org/, 2011.

${ }^{7}$ Wilbarger, J., and Howe, S. Current Practices in Engineering Capstone Education: Further Results from a 2005 Nationwide Survey. In Proceedings. Frontiers in Education. 36th Annual Conference, 5-10. IEEE, October 2006. 